\title{
marges Marges
}

revue d'art contemporain Revue d'art contemporain

\section{William Forsythe - In the Company of Others}

21 novembre 2015 - 21 février 2016, Kunsthal Charlottenborg, Copenhague

\section{Umut Ungan}

\section{(2) OpenEdition}

1 Journals

Édition électronique

URL : http://journals.openedition.org/marges/1213

DOI : $10.4000 /$ marges. 1213

ISSN : 2416-8742

Éditeur

Presses universitaires de Vincennes

\section{Édition imprimée}

Date de publication : 20 octobre 2016

Pagination : 134-135

ISBN : 978-2-84292562-8

ISSN : $1767-7114$

\section{Référence électronique}

Umut Ungan, « William Forsythe - In the Company of Others », Marges [En ligne], 23 | 2016, mis en ligne le 20 octobre 2016, consulté le 25 septembre 2020. URL : http://journals.openedition.org/ marges/1213; DOI : https://doi.org/10.4000/marges.1213 


\section{«William Forsythe - \\ In the Company of Others »}

21 novembre 2015 - 21 février 2016, Kunsthal Charlottenborg, Copenhague

Il existe sûrement une tentation institutionnelle, amplifiée par un intérêt médiatique ou autre, d'exploiter les possibilités que peut offrir le projet d'une exposition autour d'un artiste qui s'illustre dans différents domaines et d'autant plus si les délimitations de ces derniers au sein de sa pratique sont, volontairement ou involontairement, floues. En ce sens, la forme de "défi » que peut représenter habituellement ce type d'activité artistique est aussi une forme d'opportunité qui permet à l'institution de se singulariser par rapport aux expositions habituelles, qu'elles soient monographiques ou collectives. Celle de William Forsythe, "In the Company of Others», incarne ce type d'occasion: il est un artiste/chorégraphe, qui produit aussi bien depuis plus d'une quarantaine d'années des spectacles chorégraphiques que des "objets chorégraphiques", installations comprenant la "participation" active des visiteurs. II représente, parmi d'autres, la figure du créateur transdisciplinaire, œuvrant selon un degré d'abstraction élevé du genre qu'est la danse, ce qui lui permet un accueil plus que favorable dans les centres d'art contemporain. Le choix des œuvres exposées à la Kunsthal Charlottenborg s'appuie à la fois sur les "objets chorégraphiques" et deux vidéos "performatives», Suspense (2008) et Stellenstellen (2013), augmentés des œuvres de "The Others", un ensemble de sept artistes qui « donnent vie aux différents projets» du chorégraphe/artiste, comme l'explique la présentation. Cette "compagnie temporaire » est inévitablement une compagnie arbitraire, relevant davantage de l'intention curatoriale que celle des artistes, comme peuvent laisser présager les mots de la présentation. Elle se justifie, conceptuellement parlant, sur un double plan : générique, où la chorégraphie est entendue comme danse; conceptuel, où la danse est "réduite » à l'idée de corps. Selon la première voie, on retrouve une vidéo de Manon de Boer filmant la danseuse Cynthia Loemij, à partir d'une composition du musicien belge 
Eugène Ysaye; celle de Rashaad Newsome qui réalise un mélange chorégraphique de voguing, forme de danse populaire dans les années 1960-1970 au sein de l'underground new-yorkais; ou encore Sturtevant qui reproduit une œuvre de Felix Gonzales-Torres qui consiste en une performance aléatoire d'un danseur durant l'exposition sur un podium éclairé, écoutant son walkman. Du côté du "corps ", on retrouve la vidéo de la performance historique de Bruce Nauman In Walk with Contrapposto (1968) ou encore les chaises "concrètes " de Magnus Pettersen, Soft (2015) qui invitent les visiteurs à s'asseoir pour regarder Stellenstellen de Forsythe, jouant de l'ambiguïté entre l'objet fonctionnel et l'objet artistique. Dans l'exposition on trouve des œuvres plus en marge de ces deux conceptions de la chorégraphie mais qui peuvent tout de même s'y rattacher, comme la projection de Gerard Byrne prenant pour objet la reconstitution de la sculpture en mica et verre de Robert Smithson qui date de 1968 par deux conservateurs de la National Gallery of Denmark, ou la vidéo de Maria Meinild qui filme un groupe d'individus s'adonnant à une série de performances rappelant des thérapies collectives, augmentées d'une voix off robotisée. L'aspect très hétéroclite de cette " compagnie » arbitraire se veut comme une éventuelle réponse aux œuvres exposées de Forsythe. Ces dernières font appel principalement au statut du visiteur comme corps mobilisé dans un espace, comme avec Nowhere and Everywhere at the Same Time (2005-2015), assurément l'œuvre phare de l'exposition qui investit une salle entière avec les pendulum qui obligent à prendre conscience de ses propres mouvements; The Defenders Part 3 (2009) où le visiteur est invité à lire un prompteur d'une caméra de télévision; ou encore Toward the Diagnostic Gaze (2013) où il est demandé de tenir fixement un plumeau dépoussiérant. À ces choreographic objects s'ajoute la vidéo-performance de Forsythe lui-même, Suspense (2008), avec deux caméras qui le filment dans une volonté de s'immobiliser avec des cordes et Stellenstellen, installation composée de deux écrans prenant pour objet deux danseurs qui combinent leurs corps selon une forme sculpturale. En incluant d'autres artistes de différentes générations à partir d'un concept (avec le terme Company qui joue à la fois sur le registre du genre artistique et celui du mode organisationnel) qui ne se révèle que trop peu opérant et « léger » sur le plan pratique, les travaux de Forsythe, bien qu'ils constituent un intérêt indéniable pour l'expérience du visiteur, malgré leur nombre (cinq au total) et leur mise en scène réduits, semblent plutôt se perdre dans cet ensemble très hétérogène d'œuvres. II semble inévitable que le haut degré d'abstraction qui travaille le genre chorégraphique et ses formes contemporaines ne puisse revêtir un intérêt pratique que si l'on modifie également les modalités d'exposition traditionnelles. Faute de quoi, on ne peut qu'observer sa dissolution dans une exposition classique qui reste, somme toute, une mise en vue d'une suite d'objets. Une des conséquences fâcheuses de cette asymétrie entre la production et sa médiation est l'aspect arbitraire qui, inhérent à tout choix, devient manifeste et bien trop visible. Dans son interview de la présentation, Forsythe affirme que «la chorégraphie n'est généralement qu'un prétexte pour l'action ». Si cela peut constituer une réelle potentialité pour le travail et la pensée artistique, on voit que cela représente davantage un piège pour l'activité curatoriale et institutionnelle qui désire l'exploiter sans se questionner.

\section{Umut Ungan}

